\title{
Транспорт и фоточувствительность в структурах: композитный слой из наночастиц кремния и золота на $p$-Si
}

\author{
(C) М.П. Тепляков ${ }^{1}$, О.С. Кен ${ }^{2}$, Д.Н. Горячев ${ }^{2}$, О.М. Сресели ${ }^{2}$ \\ ${ }^{1}$ Санкт-Петербургский политехнический университет Петра Великого, \\ 195251 Санкт Петербург, Россия \\ ${ }^{2}$ Физико-технический институт им. А.Ф. Иоффре Российской академии наук, \\ 194021 Санкт Петербург, Россия \\ E-mail: twarm@mail.ru
}

(Получена 26 февраля 2018 г. Принята к печати 12 марта 2018 г.)

Исследованы температурные зависимости вольт-амперных характеристик и фоточувствительности структур из композитных слоев наночастиц кремния и золота на монокристаллическом кремнии $p$-типа проводимости. Определены механизмы переноса тока в структурах и их влияние на фоточувствительность структур с разным количеством золота в композитном слое.

DOI: $10.21883 /$ FTP.2018.09.46232.8852

\section{1. Введение}

Улучшение параметров фотодетекторов и солнечных элементов - одно из основных направлений физики полупроводников, которое стало особенно перспективным после создания полупроводниковых слоев с квантоворазмерными частицами, позволяющими моделировать запрещенную зону полупроводника (далее - композитные слои) [1,2]. При этом композитные слои с кремниевыми наночастицами особенно важны для этих работ, так как кремний является основным материалом электроники. В то же время механизмы переноса носителей в структурах с наночастицами изучены относительно слабо [3-5], хотя они очень важны для создания эффективных приборов.

Ранее нами были исследованы композитные слои, состоящие из наночастиц аморфного кремния (nano-Si) и наночастиц золота, полученные лазерным электродиспергированием [6]. Было показано, что структуры, состоящие из такого композитного слоя на подложке монокристаллического кремния $p$-типа проводимости, обладают огромной спектральной чувствительностью (до $20 \mathrm{~A} / \mathrm{BT}$ ) и усилением фототока. Обнаружение внутреннего усиления в таких фактически фотодиодных структурах свидетельствует о существовании дополнительного механизма токопрохождения, связанного с композитным слоем и гетерограницей. Были предложены две модели усиления фототока - на основе эффекта усиления фотопроводимости и транзисторного эффекта. В обоих случаях важную роль играет захват фотоносителей одного типа ловушками в композитном слое или на границе слой-подложка, а для получения больших коэффициентов усиления важно, чтобы время прохождения через композитный слой фотоносителей другого типа было как можно короче.

Целью данной работы было определение механизмов переноса тока в структурах и их влияние на фоточувствительность структур с разным количеством золота в композитном слое. Проведены исследования темпе- ратурных зависимостей вольт-амперных характеристик и спектров фоточувствительности структур с разным количеством золота в композитном слое.

\section{2. Методика эксперимента}

Были исследованы структуры с композитными слоями, состоящими из аморфных наночастиц кремния и золота в различных соотношениях, на подложках монокристаллического кремния $p$-типа проводимости. Образцы изготавливались методом лазерного электродиспергирования [6,7]. Основное внимание будет уделено образцу 1 со слоем наночастиц кремния без золота и образцу 2 с высоким содержанием наночастиц $\mathrm{Au}$ (соотношение $\mathrm{Si}: \mathrm{Au} \sim 1: 1)$, который обладает значительным усилением фототока.

Измерялись темновые вольт-амперные характеристики (BAX) и спектры фоточувствительности структур при температурах от $110-120 \mathrm{~K}$ до комнатной.

Темновые ВАХ были получены при помощи потенциостата P-8nano. При измерении BAX прямое смещение соответствовало приложению отрицательного потенциала к золотому сеточному контакту на поверхности композитного слоя, а положительного потенциала к вплавленному Al-контакту на $p$-Si.

Спектры фоточувствительности регистрировались при возбуждении светом галогеновой лампы „OSRAM“, прошедшим через механический обтюратор и монохроматор

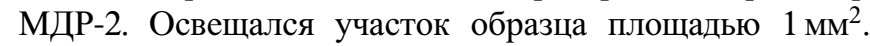
Для измерения мощности прошедшего через монохроматор света использовался калиброванный кремниевый фотодиод ФДУК-100УТ [8]. На исследуемые образцы подавалось обратное напряжение (т.е. подложка $p$-Si была под отрицательным потенциалом) величиной $\sim 1.3$ В. Регистрация фототока осуществлалась при помощи селективного усилителя У2-8 на частоте модуляции (40 Гц). При помощи аналого-цифрового преобра- 
зователя сигнал с У2-8 поступал на компьютер, где и происходила его дальнейшая обработка.

Для измерения температурных зависимостей исследуемые образцы были укреплены на медном хладопроводе азотного оптического криостата с сапфировым окном. Температура хладопровода контролировалась при помощи термопары медь-константан. После максимального охлаждения хладопровода и структур жидким азотом происходило измерение спектров фоточувствительности в процессе отогревания образцов до комнатной температуры $(T \sim 110-297 \mathrm{~K})$. Разброс температур при измерении каждого спектра указан в подписях к рисункам.

\section{3. Результаты экспериментов и их обсуждение}

\section{1. Вольт-амперные характеристики}

Вольт-амперные характеристики образцов выпрямляющие, но с разным коэффициентом выпрямления для образцов с разным количеством золота в композитном слое. При понижении температуры увеличивается нелинейность характеристик и растет величина напряжения отсечки (рис. 1).

Поскольку исследованные структуры, как было показано ранее [9], представляют собой $p-n$-гетероструктуры, то прямые ветви ВАХ можно описать известным выражением

$$
I \propto \exp (q U / n k T),
$$

где $q-$ модуль заряда электрона, $k-$ постоянная Больцмана, $T$ - температура, $n-$ коэффициент неидеальности, $U$ и $I-$ текущие значения напряжения и тока структуры.

Анализ прямой ветви образца без золота (образец 1) показал, что при напряжениях до $100 \mathrm{MB}$ она описывается экспонентой с коэффициентом неидеальности $\sim 2$, что типично для структуры с токами, ограниченными объемным зарядом (ТОО3), и генерационнорекомбинационными токами в области пространственного заряда. Это же подтверждает и обратная ветвь $\mathrm{BAX}$ - ток растет с увеличением смещения.

Для наглядности прямые ветви ВАХ образца без золота, измеренные при температурах от 134 до $297 \mathrm{~K}$, представлены на рис. 2 в двойном логарифмическом масштабе. Они могут быть аппроксимированы отрезками прямых и описаны степенной зависимостью $I \propto U^{m}$ с разными показателями степени $m$, характеризующими наклон соответствующего участка. Наблюдаются два участка: первый - с обычным наклоном $(m=1-2)$, и значительно более крутой, с $m>(4-5)$, при бо́льших смещениях. Для разных температур большое значение $m$ остается примерно постоянным. С уменьшением температуры участок пологого роста тока сокращается, а начало резкого роста тока сдвигается в сторону бо́льших напряжений - растет напряжение отсечки.

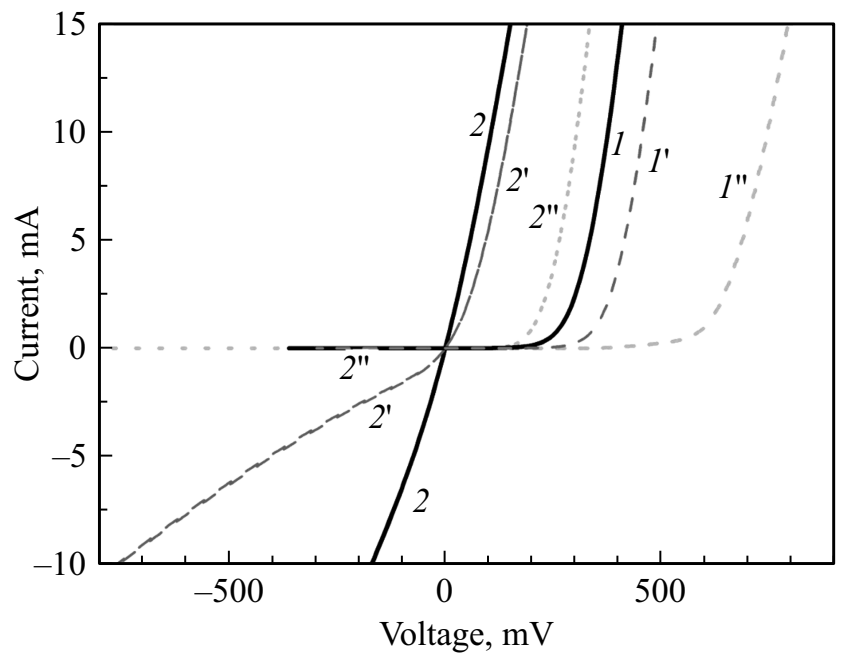

Рис. 1. Температурная зависимость ВАХ образцов: $1,1^{\prime}$, $1^{\prime \prime}$ - без золота, температуры $297,(266-269)$ и $(186-189) \mathrm{K}$ соответственно; 2, 2', $2^{\prime \prime}$ - объемная доля золота 50\%, температуры 297, (260-261) и (186-189) К соответственно.

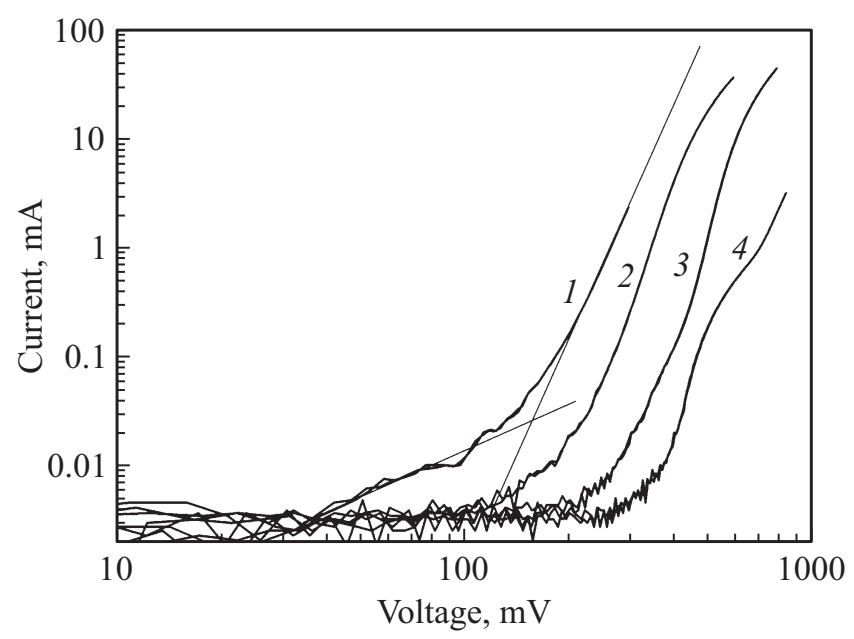

Рис. 2. ВАХ образца 1 (без золота). Температура $T, \mathrm{~K}$ : $1-297,2-(266-269), 3-(202-206), 4-(134-145)$.

Увеличение напряжения отсечки свидетельствует о росте барьера на гетерогранице слой-подложка. В то же время, крутизна второго участка ВАХ практически не зависит от температуры. Отсюда можно сделать вывод, что этот участок ВАХ определяется туннельным током в композитном слое. Об этом свидетельствует также линейность кривых, перестроенных в координатах Фаулера-Нордгейма, $\ln \left(I / U^{2}\right)-1 / U$, и Абелеса, $\ln (I / U)-1 / U$. Судя по всему, происходит туннелирование носителей заряда между наночастицами кремния в слое, скорее всего, по уровням дефектов на поверхности наночастиц. Однако возможно и прямое туннелирование как между основными, так и между возбужденными состояниями наночастиц (квантовых точек), аналогично [10]. 
Однозначно определить энергию активации для этих уровней по температурным зависимостям ВАХ оказалось трудно: поскольку на ВАХ нет явных изломов и прямых участков, можно предположить, что уровни распределены в некотором диапазоне энергий, по данным эксперимента это $0.05-0.15$ эВ. Полученные в работе [11] значения энергии основного и возбужденного состояний носителей заряда в квантовых точках кремния в слоях nano-Si лежат в этом же диапазоне энергий.

Интерес представляет резкое отличие ВАХ образца 2 с большим количеством золота ( $\mathrm{Si}: \mathrm{Au} \sim 1: 1)$ по сравнению с образцом 1. При комнатной температуре ВАХ почти линейна. При понижении температуры обратный ток резко падает и уже при $-50^{\circ} \mathrm{C}(227 \mathrm{~K})$ ВАХ имеет четко выпрямляющий характер (см. рис. 1 кривые $\left.2,2^{\prime}, 2^{\prime \prime}\right)$.

На основе анализа ВАХ структур с разными составами композитного слоя в работе [6] была предложена эквивалентная схема структур, состоящая из фотодиода и фотосопротивления, включенных параллельно. Это позволило объяснить большую фоточувствительность структур за счет механизма усиления фотопроводимости [12]. Предполагалось, что в композитном слое перенос фотоносителей может происходить по двум типам каналов: первый включает только цепочки наночастиц $\mathrm{Si}$, которые образуют выпрямляющий контакт с подложкой, а второй - наночастицы как $\mathrm{Si}$, так и $\mathrm{Au}$, при этом последние образуют с подложкой омический контакт. В результате в композитном слое существуют цепочки из аморфных наночастиц кремния - сопротивления, включенные параллельно гетеропереходу подложка-наночастицы кремния.

Мы провели расчет величины параллельного сопротивления $R_{p}$, исходя из формулы для тока в структуре:

$$
I=I_{0}\left(\exp \left(q \frac{U-I R_{s}}{k T}\right)-1\right)+\frac{U-I R_{s}}{R_{p}},
$$

где $R_{s}$ - последовательное сопротивление, $R_{p}-$ параллельное сопротивление, $I_{0}$ - ток насыщения гетероперехода. На рис. 3 показаны ВАХ образца 2 при разных температурах: экспериментальные и полученные по формуле (2). Из рисунка видно, что расчетные кривые хорошо согласуются с экспериментальными при значениях $R_{p}, R_{s}$ и $I_{0}$, показанных в таблице. С понижением температуры резко увеличивается сопротивление $R_{p}$ и характеристика становится выпрямляющей.

Расчетные параметры BAX

\begin{tabular}{c|c|c|r}
\hline$T, \mathrm{~K}$ & $R_{p}, \mathrm{OM}$ & $R_{s}, \mathrm{OM}$ & \multicolumn{1}{c}{$I_{0}, \mathrm{~A}$} \\
\hline 297 & 13.3 & 7.3 & $5 \cdot 10^{-3}$ \\
270 & 35 & 7.13 & $2.3 \cdot 10^{-3}$ \\
260 & 73 & 6.57 & $0.42 \cdot 10^{-3}$ \\
250 & 155 & 6.29 & $0.11 \cdot 10^{-3}$ \\
227 & 1098 & 5.53 & $0.5 \cdot 10^{-5}$ \\
186 & 432500 & 4.3 & $1 \cdot 10^{-9}$
\end{tabular}

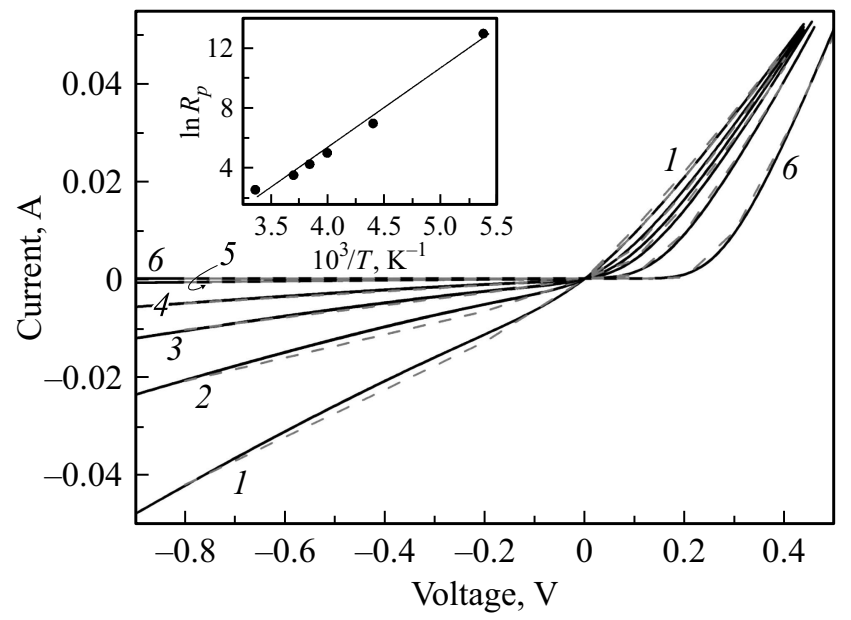

Рис. 3. Расчетные (пунктир) и экспериментальные (сплошные линии) температурные зависимости ВАХ образца 2. T, К: $1-297,2-270,3-260,4-250,5-227,6-$ 186. На вставке - зависимость логарифма $R_{p}$ от обратной температуры.

Зависимость $R_{p}$ от обратной температуры носит экспоненциальный характер (вставка на рис. 3), при этом активационная энергия проводимости равна 0.43 эВ.

Таким образом, с понижением температуры сопротивление структуры $R_{p}$ резко увеличивается и ВАХ становится выпрямляющей, т.е. при низких температурах перенос тока происходит в основном по фотодиодной ветви - через гетеробарьер. Поскольку фотодиод не обладает внутренним усилением, то с понижением температуры коэффициент усиления структуры уменьшается до единицы. В связи с этим должен происходить спад фоточувствительности.

Таким образом, анализ ВАХ показал, что механизм протекания тока в исследованных структурах меняется с ростом приложенного напряжения. При небольших напряжениях в пропускном направлении наблюдаются TOO3, их сменяет туннелирование по уровням наночастиц кремния, скорее всего поверхностным. При большом количестве частиц золота в композитном слое гетеродиодная структура превращается в структуру с параллельным переходу омическим сопротивлением, причем с уменьшением температуры это сопротивление экспоненциально возрастает, и уже при $227 \mathrm{~K}$ структура с композитным слоем $\mathrm{Si}-\mathrm{Au}$ становится диодной.

\section{2. Фоточувствительность образцов}

Фоточувствительность образцов уменьшается с понижением температуры. Для спектров всех образцов характерен сдвиг длинноволнового пика в сторону меньших длин волн с понижением температуры.

Спектры фоточувствительности образца 1 (без золота) при разных температурах изображены на рис. 4. Уменьшение температуры от комнатной до $113 \mathrm{~K}$ приво- 
дит к уменьшению величины чувствительности образца более чем в 9 раз. Меняется и форма спектра. При комнатной температуре $(297 \mathrm{~K})$ наблюдается один пик на длине волны $\lambda \approx 900$ нм. С понижением температуры этот пик сдвигается в сторону меньших длин волн и появляется коротковолновое плечо.

Величина фоточувствительности образца 2 при комнатной температуре (рис. 5, кривая 1) свидетельствует о существовании усиления фототока в структуре. Предполагается [6], что в сопротивлении $R_{p}$ наблюдается усиление фотопроводимости. Это возможно, если время пролета фотоносителей через фотопроводник $\left(T_{\mathrm{tr}}\right)$ меньше времени жизни $(\tau)$. Тогда коэффициент усиления фотопроводимости есть $G=\tau / T_{\mathrm{tr}}$ [12]. Фоточувствительность этого образца при понижении температуры от 297 до $123 \mathrm{~K}$ падает еще сильнее, чем у образца 1 почти на 3 порядка (рис. 5).

Для анализа зависимости формы спектров фоточувствительности от температуры удобнее изобразить их в нормированном на 1 масштабе (см. рис. 6). В спектре фоточувствительности при комнатной температуре можно выделить длинноволновый пик $(\lambda \approx 970$ нм $)$ и коротковолновое плечо $(\lambda \approx 500 \mathrm{HM})$. С понижением температуры наблюдается сдвиг длинноволнового пика в сторону коротких волн, а затем его исчезновение. При температуре $<200 \mathrm{~K}$ длинноволновый пик практически пропадает, но при этом остается коротковолновый максимум.

Таким образом, наблюдаются следующие изменения фоточувствительности образцов:

- C понижением температуры фоточувствительность уменьшается, причем особенно сильно в образцах с внутренним усилением. Ослабление фоточувствительности с понижением температуры во всех рассмотренных случаях свидетельствует о том, что механизмы токопрохождения определяются барьерными процессами прыжковой проводимостью, туннелированием, активационными процессами через уровни, причем как на поверхности наночастиц кремния, так и на гетерогранице композитный слой-подложка.

- Фоточувствительность при понижении температуры изменяется неравномерно по спектру. Край поглощения слоя наночастиц кремния сдвинут в коротковолновую область по отношению к краю поглощения монокристаллического кремния [13], что позволяет связать коротковолновый максимум с генерацией фотоносителей заряда в слое наночастиц. Длинноволновый же максимум можно отнести к генерации носителей заряда в кремниевой подложке, так как и его положение, и сдвиг при понижении температуры примерно соответствуют величине и изменению с температурой ширины запрещенной зоны объемного кремния.

В образце 2 (с большим содержанием Аu в композитном слое) с понижением температуры фоточувствительность падает особенно сильно и пропадает внутреннее усиление.

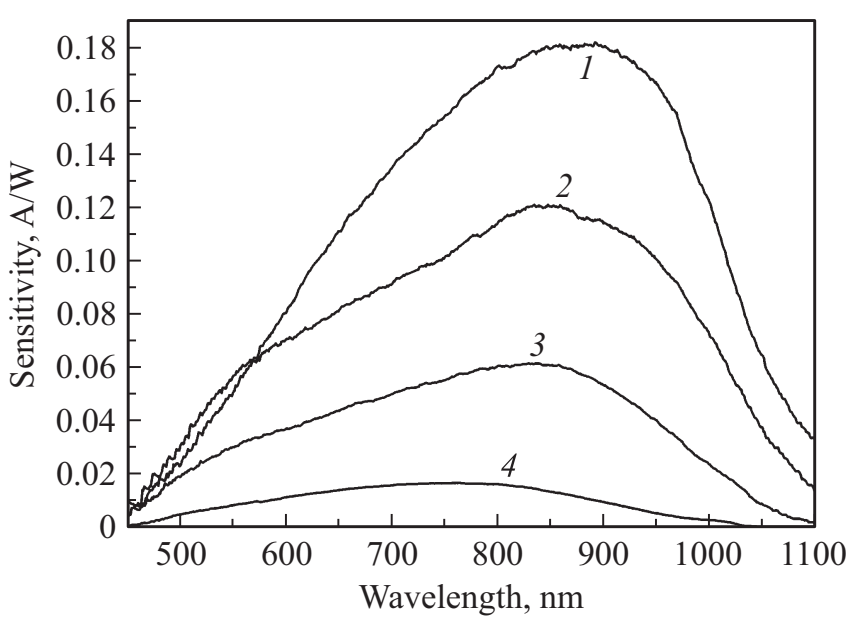

Рис. 4. Спектры фоточувствительности образца 1 при различных температурах. Величина обратного смещения на образце $U=1.32$ B. $T, \mathrm{~K}: 1-297,2-(238-242), 3-(192-199)$, $4-(113-118)$.

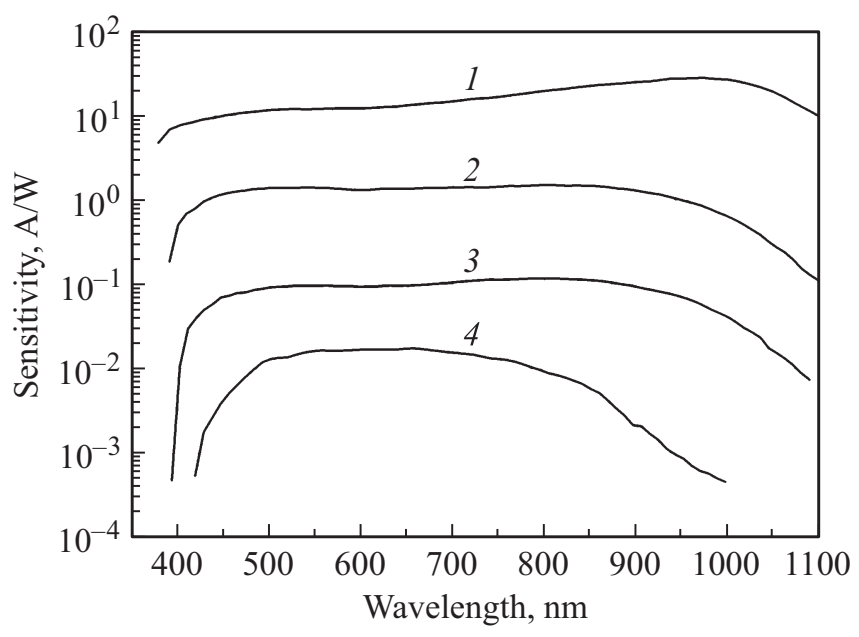

Рис. 5. Спектры фоточувствительности образца 2 в полулогарифмическом масштабе при различных температурах и обратном смещении $U=1.22$ В. $T, \mathrm{~K}: 1-297,2-(219-225)$, $3-(211-217), 4-123$.

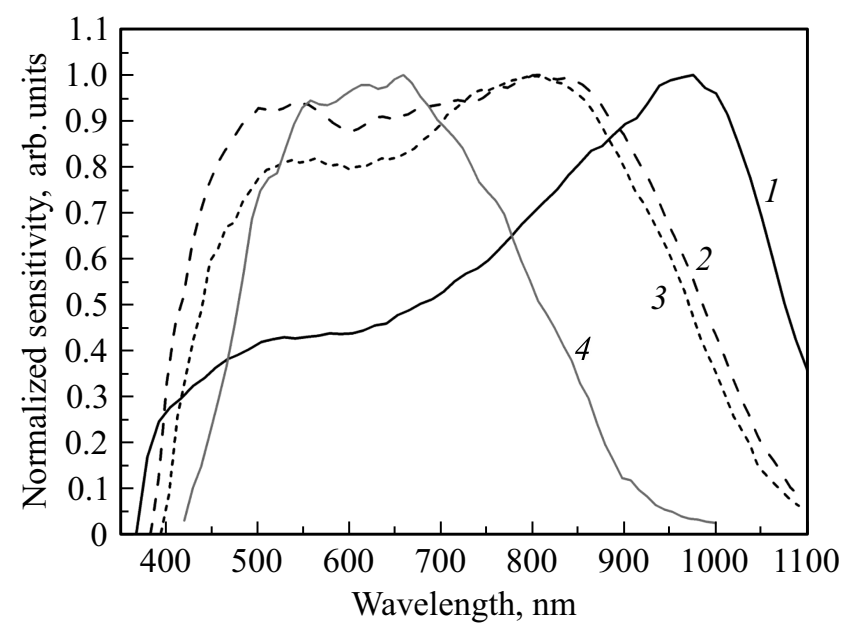

Рис. 6. Нормированные на единицу спектры фоточувствительности образца 2 при различных температурах. $T, \mathrm{~K}: 1-297$, 2 - (219-225), $3-(211-217), 4-123$. 
Установим связь между изменением величины параллельного сопротивления $R_{p}$ и коэффициентом усиления фотопроводимости $G=\tau / T_{\text {tr }}$. Соотношение между сопротивлением $R_{p}$ и временем пролета $T_{\mathrm{tr}}$ задается известными формулами:

$$
\begin{gathered}
R_{p}=\frac{d}{\sigma S}, \\
\sigma=q n \mu, \\
T_{\mathrm{tr}}=\frac{d}{v_{\mathrm{dr}}}=\frac{d}{\mu E},
\end{gathered}
$$

где $d-$ толщина слоя, $\sigma-$ проводимость, $S-$ площадь слоя, $n$ - концентрация электронов, $\mu-$ подвижность электронов, $v_{\mathrm{dr}}-$ дрейфовая скорость, $E$ - напряженность электрического поля.

Выполняя математические преобразования соотношений (3), (4) и (5), получаем, что время пролета носителей прямо пропорционально величине параллельного сопротивления: $T_{\mathrm{tr}} \propto R_{p}$. Следовательно, коэффициент усиления обратно пропорционален этому сопротивлению: $G \propto 1 / R_{p}$. Полученный из анализа $\mathrm{BAX}$ рост сопротивления $R_{p}$ с понижением температуры образца приводит вначале к уменьшению усиления фотопроводимости, а затем и полному его исчезновению. Увеличение сопротивления обусловлено главным образом уменьшением подвижности фотоносителей. Таким образом, модель параллельно соединенных фотодиода и фотосопротивления объясняет падение коэффициента усиления при понижении температуры.

\section{4. Заключение}

Показано, что основной механизм протекания тока в структурах с композитным слоем из наночастиц $\mathrm{Si}$ и $\mathrm{Au}$ связан с туннелированием носителей через уровни в наночастицах кремния или на их поверхности. Увеличение количества наночастиц золота в композитном слое приводит к тому, что в структуре появляется параллельное гетеропереходу шунтирующее сопротивление. Определена его величина и характер ее изменения при понижении температуры.

Показана взаимосвязь температурных зависимостей BAX и фоточувствительности структур. Подтверждено предположение работы [6], что при комнатной температуре аномально большая фоточувствительность гетероструктур с большим количеством золота в композитном слое вызвана эффектом усиления фотопроводимости в композитном слое из наночастиц кремния и золота.

Показано, что понижение температуры приводит к уменьшению фоточувствительности всех структур. Особенно резко падает фоточувствительность в структурах с большим количеством золота. Обнаружено, что в этих структурах параллельное сопротивление возрастает, а время пролета фотоносителей через композитный слой увеличивается с понижением температуры практически экспоненциально. Активационная энергия этого процесса составляет 0.35-0.45 эВ. Вследствие этого усиле- ние фотопроводимости пропадает уже при охлаждении структуры ниже $230 \mathrm{~K}$.

Авторы глубоко признательны Д.А. Явсину за изготовление образцов и С.А. Гуревичу за постоянный интерес к работе и полезные обсуждения.

\section{Список литературы}

[1] D. Bera, L. Qian, T.-K. Tseng, P.H. Holloway. Materials, 3, 2260 (2010).

[2] A. Marti, A. Luque. Next Generation Photovoltaics (Bristol, Inst. of Physics, 2004) p. 332.

[3] М.Н. Солован, В.В. Брус, П.Д. Марьянчук. ФТП, 48 (7), 926 (2014).

[4] Ю.В. Рябчиков, П.А. Форш, Э.А. Лебедев, В.Ю. Тимошенко, П.К. Кашкаров, B.V. Kamenev, L. Tsybeskov. ФТП, 40 (9), 1079 (2006).

[5] В.В. Трегулов, В.А. Степанов, В.Г. Литвинов, А.В. Ермачихин. ФТП, 86 (11), 91 (2016).

[6] O.S. Ken, D.A. Yavsin, P.A. Dementev, S.A. Gurevich, O.M. Sreseli. Phys. Status Solidi A, 213 (11), 2906 (2016).

[7] V.M. Kozhevin, D.A. Yavsin, V.M. Kouznetsov, V.M. Busov, V.M. Mikushkin, S.Yu. Nikonov, S.A. Gurevich, A. Kolobov. J. Vac. Sci. Technol. B, 18, 1402 (2000).

[8] V.V. Zabrodsky, V.P. Belik, P.N. Aruev, B.Ya. Ber, S.V. Bobashev, M.V. Petrenko, V.L. Sukhanov. Tech. Phys. Lett., 38, 812 (2012).

[9] О.С. Кен, Д.А. Андроников, Д.А. Явсин, А.В. Кукин, С.Н. Данилов, А.Н. Смирнов, О.М. Сресели, С.А. Гуревич. ФТП, 48 (11), 1555 (2014).

[10] А.А. Евтух, Э.Б. Каганович, Э.Г. Манойлов, Н.А. Семененко. ФТП, 40 (2), 180 (2006).

[11] М.М. Соболев, О.С. Кен, О.М. Сресели, Д.А. Явсин, С.А. Гуревич. Письма в ЖТФ, 44 (8), 47 (2018).

[12] Т. Мосс, Г. Баррел, Б. Эллис. Полупроводниковая оптоэлектроника (М., Мир, 1976).

[13] O.S. Yeltsina, D.A. Andronikov, A.V. Kukin, J.S. Vainshtein, O.M. Sreseli. Phys. Status Solidi C, 9 (6), 1471 (2012).

Редактор Л.В. Шаронова

\section{Transport and photosensitivity in structures: composite layer with silicon and gold nanoparticles on $\mathbf{p}$-Si}

\author{
M.P. Teplyakov ${ }^{1}$, O.S. Ken ${ }^{2}$, D.N. Goryachev' ${ }^{2}$, \\ O.M. Sreseli ${ }^{2}$ \\ ${ }^{1}$ Peter the Great St. Petersburg Polytechnic University, \\ 195251 St. Petersburg, Russia \\ ${ }^{2}$ loffe Institute, \\ 194021 St. Petersburg, Russia
}

Abstract The temperature dependences of current-voltage characteristics and photosensitivity of structures consisting of composite layer with silicon and gold nanoparticles on singlecrystal $p$-type silicon are investigated. Mechanisms of current transfer in the structure and their influence on the photosensitivity of structures with different amounts of gold in the composite layer are determined. 